\title{
Status of the LHC Superconducting Cable Mass Production
}

\author{
J. D. Adam, T. Boutboul, G. Cavallari, Z. Charifoulline, C.-H. Denarie, S. Le Naour, D. F. Leroy, L. R. Oberli, \\ D. Richter, A. P. Verweij, and R. Wolf
}

\begin{abstract}
Six contracts have been placed with industrial companies for the production of 1200 tons of the superconducting (SC) cables needed for the main dipoles and quadrupoles of the Large Hadron Collider (LHC). In addition, two contracts have been placed for the supply of 470 tons of NbTi and 26 tons of $\mathrm{Nb}$ sheets. The main characteristic of the specification is that it is functional. This means that the physical, mechanical and electrical properties of strands and cables are specified without defining the manufacturing processes. Facilities for the high precision measurements of the wire and cable properties have been implemented at CERN, such as strand and cable critical current, copper to superconductor ratio, interstrand resistance, magnetization, RRR at $4.2 \mathrm{~K}$ and $1.9 \mathrm{~K}$. The production has started showing that the highly demanding specifications can be fulfilled. This paper reviews the organization of the contracts, the test facilities installed at CERN, the various types of measurements and the results of the main physical properties obtained on the first batches. The status of the deliveries is presented.
\end{abstract}

\section{INTRODUCTION}

$\mathbf{T}$ HE CONSTRUCTION of the LHC machine requires the fabrication of 1232 twin, 15-m long, dipoles and 400 two-in-one, 3.2-m long quadrupoles in the main arcs [1]. Additionally, dipoles and quadrupoles of the same type have to be installed in the lines between the main arcs and the experiments. Dipoles and quadrupoles are powered in a separated electrical serial connection, and distributed equally in 8 octants. A total of $160 \mathrm{~km}$ of SC bus-bars will connect the dipoles and the two types of quadrupoles (focusing and defocusing).

The dipoles will operate at $1.9 \mathrm{~K}$ at an envisaged operating field of up to $9 \mathrm{~T}$. The design is based on a two-layer $\cos \theta$ structure with grading between the inner and outer layer using two different SC cables, in order to reduce the cost and the field distortions at injection.

The three main points in this design are:

- The quantity of superconductor material is determined considering the actual maximum field seen by the strands of that layer.

- The quantity of copper in each layer is determined so that the magnets can be safely protected in case of a quench. The optimization of the $\mathrm{Cu} / \mathrm{SC}$ ratio takes into account that the firing quench heaters are located on the external surface of the outer layer of cables in which, as a consequence, most of the dissipated energy will be absorbed in case of a quench.

Manuscript received September 24, 2001.

The authors are with C.E.R.N., Geneva 23, CH-1211 Swizterland (e-mail: dfl@cern.ch).

Publisher Item Identifier S 1051-8223(02)03888-5.
- The diameters (and hence the magnetization) of the NbTi filaments in the strands of each cable are a balance between the manufacturing cost and the quality of the magnetic field (mainly the sextupole and the decapole components) at the injection field (0.5 T).

The cables for the inner and outer layer of the main dipole magnets are called Cable 01 and Cable 02 respectively. It has been decided, for economical reasons, to use for the quadrupole cables and the bus-bars the same cable as the outer cable of the dipoles. The quadrupole cables are called Cable 03. In total LHC requires the fabrication of $7000 \mathrm{~km}$ of cable, corresponding to about $240000 \mathrm{~km}$ of strand, manufactured from about 7000 NbTi billets.

A strong Quality Assurance system, based on Statistical Process Control (SPC) methods, has been put in place in order to ensure the homogeneity of the production and increase the confidence in the quality of the SC cables. Key characteristics of the strand and cable are measured and displayed during the entire manufacturing period. A center line and upper and lower control limits are defined so that, when the process is in control, nearly all the sample points will fall between the control limits. A point outside the control limits requires a corrective action from the manufacturer to eliminate the cause. The control limits have to fall inside the specification limits. The target is to have the control limits at $\pm 3 \sigma$ of the statistical distribution.

Each strand manufacturer has to perform systematic quality control on the strands and cables. CERN has installed a dedicated test laboratory (see Section IV) for various cold and warm measurements to verify the results from industry.

In Section II the specification of the cables will be briefly described with emphasis on some specific characteristics. In Section III some organization features of the contracts are described. In the last sections some results are presented of the cables as produced so far and a status is given of the actual and planned production.

\section{SPECIFICATION}

Table I shows the main characteristics of the main arc dipole and quadrupole cables specified for LHC.

The LHC critical current density in each strand has been optimized to have the largest possible critical current density $\left(J_{C}\right)$ at $9-10 \mathrm{~T}$ at $1.9 \mathrm{~K}$ while, at the same time, reducing as much as possible the $J_{C}$ at $0.5 \mathrm{~T}$ and $1.9 \mathrm{~K}$.

Two specific requirements of the LHC cable specification concern constraints on the magnetization $(M)$ and the interstrand contact resistance $(R c)$, both more stringent as compared to previous superconducting accelerator magnets. They are due 
TABLE I

MaIN CHARACTERISTICS OF THE SUPERCONDUCTING CABLES

\begin{tabular}{|c|c|c|}
\hline STRAND & Type 01 & Type 02 \\
\hline Diameter (mm) & 1.065 & 0.825 \\
\hline $\mathrm{Cu} / \mathrm{SC}$ ratio & $1.6-1.7$ & $1.9-2.0$ \\
\hline $\mathrm{Cu} / \mathrm{SC}$ control limits & \pm 0.03 & \pm 0.03 \\
\hline Filament diameter $(\mu \mathrm{m})$ & 7 & 6 \\
\hline Twist pitch (mm) & 18 & 15 \\
\hline Number of filaments & 8800 & 6425 \\
\hline Strand $I_{C}(A)$ & $515 @ 1.9 \mathrm{~K}, 10 \mathrm{~T}$ & $380 @ 1.9 \mathrm{~K}, 9 \mathrm{~T}$ \\
\hline$I_{C}$ control limits $[\%]$ & \pm 4 & \pm 4 \\
\hline $\mathrm{Jc}\left(\mathrm{A} / \mathrm{mm}^{2}\right)$ & $1530 @ 1.9 \mathrm{~K}, 10 \mathrm{~T}$ & $2100 @ 1.9 \mathrm{~K}, 9 \mathrm{~T}$ \\
\hline $\mathrm{M}(0.5 \mathrm{~T}, 1.9 \mathrm{~K})[\mathrm{mT}]$ & 30 & 23 \\
\hline $\mathrm{M}$ control limits [\%] & \pm 4.5 & \pm 4.5 \\
\hline CABLE & Type 01 & Type $02 \& 03$ \\
\hline Number of strands & 28 & 36 \\
\hline Width $(\mathrm{mm})$ & 15.1 & 15.1 \\
\hline Thickness thin edge [mm] & 1.736 & 1.362 \\
\hline Thickness thick edge [mm] & 2.064 & 1.598 \\
\hline Mid-thickness (50MPa) [mm] & $1.900+/-0.006$ & $1.480+/-0.006$ \\
\hline Keystone angle [deg] & $1.25+/-0.05$ & $0.90+/-0.05$ \\
\hline Transposition pitch (mm) & 115 & 100 \\
\hline Cable $I_{\mathbf{C}}[\mathrm{A}]$ & $13750 @ 1.9 \mathrm{~K}, 10 \mathrm{~T}$ & $12960 @ 1.9 \mathrm{~K}, 9 \mathrm{~T}$ \\
\hline Cabling degradation [\%] & $<5$ & $<5$ \\
\hline Inter-strand resistance $[\mu \Omega]$ & $10-20$ & $20-40$ \\
\hline
\end{tabular}

to a larger dynamic range of the field in the magnets (from injection to operating field) and a larger width of the cables.

\section{A. Magnetization}

The LHC cables require a high current density $J_{C}$ at high field and a low magnetization (being proportional to $J_{C}$ times the filament diameter) at low field, in order to reduce field distortions. Measurements of the strand magnetization loop [2] and simulations of the magnet harmonics during the $R \& D$ phase have lead to the choice of $7 \mu \mathrm{m}$ for strand 01 and $6 \mu \mathrm{m}$ for strand 02 or a maximum width of magnetization loop (at $0.5 \mathrm{~T}, 1.9 \mathrm{~K}$ ) of $30 \mathrm{mT}$ and $23 \mathrm{mT}$ respectively. The filament sizes of strand 01 and 02 are chosen in order to limit the negative sextupolar harmonic content at injection [3].

\section{B. Re Control}

Another important aspect of the LHC cables is a better quantitative control of $R c$, not only to reduce the cable losses during a field sweep but more importantly to limit the harmonic errors during the ramp-up of the machine. In a transposed cable coupling currents are induced between strands when submitted to a varying magnetic field. These coupling currents increase strongly with increasing cable size and are inversely proportional to $R c$ and can therefore, for a given cable, only be limited by increasing $R c$. However, a large $R c$ reduces the current sharing capabilities of the cable and hence the stability of the magnet at high fields. For these reasons $R c$ is specified to be the minimum value which can be allowed from the point of view of beam optics [4].

$R c$ is controlled by adding a fixed layer of $\mathrm{SnAg}$ on the strands followed by a cable heat treatment (HT) in air [5], [6]. Without HT $R c$ would be smaller than $1 \mu \Omega$ after coil curing. During this heat treatment $\mathrm{Sn}$ diffuses in the copper which is

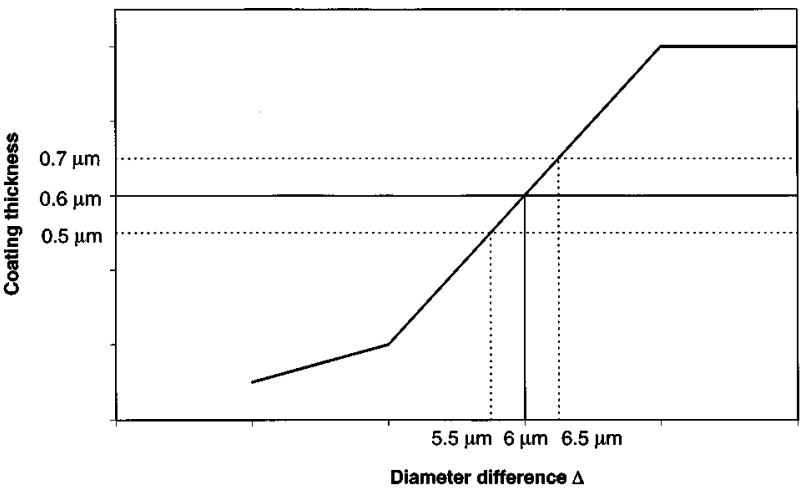

Fig. 1. Correlation of the difference $\Delta$ between the diameters of the bare wire and the wiping die and the SnAg coating thickness.

then oxidized, causing the required increase in $R c$. Typically a $0.5 \pm 0.1$ micrometer thick layer on the strands requires a cable heat treatment of about 8 hours at $200{ }^{\circ} \mathrm{C}$ to obtain the required $R c$. A thicker $\mathrm{SnAg}$ layer (about $1 \mu \mathrm{m}$ ) leads to too long HT duration, whereas a thinner $\mathrm{SnAg}$ layer requires a HT which is too short to be uniform over the entire spool. After cabling, the cables are wound on a metallic spool with a stainless steel mesh separating each layer to allow the hot air circulation between the cable layers in the oven. A cable, heat treated at $200{ }^{\circ} \mathrm{C}$ for several hours, has a contraction of less than $7 \cdot 10^{-4}$ avoiding additional thermal contraction of the coil during curing at $190^{\circ} \mathrm{C}$ for $30 \mathrm{~min}$.

A process for controlling the SnAg layer has been implemented by each company. The required $\mathrm{SnAg}$ layer is obtained by passing the bare strand through a SnAg bath at given speed and temperature. Directly in series with the bath a so-called wiping die is placed. The exact diameter of the wiping die in relation to the diameter of the bare strand and the tinning bath properties determine the final thickness of the SnAg layer (see Fig. 1). It took some time to put in operation this technology but now control to within $0.1 \mu \mathrm{m}$ is achieved. The layer thickness is checked by a coulometric methodology during the coating process.

The relationship between the coating thickness and the diameter difference between the bare wire and the wiping die has to be established for each coating line since it depends on the strand speed and the tin bath temperature of the coating process. Typically $0.6 \mu \mathrm{m}$ thick coating can be obtained with a diameter difference of about $6 \mu \mathrm{m}$. A very precise measurement of the diameters of the wire and the die is an important feature of this technology.

\section{ORGANIZATION OF THE CONTRACTS}

\section{A. Allocation of the Contracts}

Each two-in-one dipole consists of 4 unit lengths (ULs) of Cable 01 and 4 ULs of Cable 02, while one twin aperture quadrupole consists of 2 ULs of Cable 03 (PS: each UL will later on be cut in 4 pieces by the magnet manufacturer). The LHC cable contracts have been distributed among the main strand and cable suppliers all over the world resulting in an economical competition localized in the regions of the main contributors to the LHC project (Europe, Japan, USA). Table II 
shows the allocation of the various contracts signed in 1998 and slightly modified in 2000 .

\section{B. Raw Material}

All the LHC cables are manufactured from $\mathrm{NbTi}$ and $\mathrm{Nb}$ supplied by Wah-Chang, USA.

The NbTi bars and $\mathrm{Nb}$ sheets for the European strand manufacturers are part of the USA contribution to LHC, and are supplied according to a Technical Specification (TS) approved by the partners (strand manufacturers, CERN and Wah-Chang). The contract awarded to Wah-Chang (USA) concerns the supply of 470 tons of $\mathrm{NbTi}(47.0 \pm 1.0 \%$ weight Ti) and 26 tons of reactor grade $\mathrm{Nb}$ sheets. The relationship between the partners is described precisely in the terms of the contracts (certificate contents, data base, SPC follow-up, approval criteria...).

The other suppliers (Furakawa and IGC) have their own TS and provide CERN with a copy of the certificates of the raw material they use for the LHC production.

The suppliers must also give to CERN copies of the certificates for the copper used in each step of the production: mono-billet, multi-billet of stacking stage 1 and 2 .

\section{Organization of a Cabling Run}

For LHC it is required that 4 ULs of each cable are produced in the same cabling run and receive the same HT. This guarantees that the 4 ULs are as similar as possible, resulting in the best possible coil symmetry in a magnet.

Cold welds within a UL are forbidden, but can be used in between ULs to make it possible to produce long cabling runs. Very good traceability is required of the distribution of the ULs and the cold welds within the cabling run.

During cabling the relative cable dimensions (width, mid-thickness, and keystone angle) are recorded on-line using a so-called CMM (Cable Measuring Machine) - developed in the US - using a transverse pressure of $20 \mathrm{MPa}$. Moreover, at the beginning and the end of the cabling run the absolute value of the mid-thickness of the cable is measured on a stack of 10 cables compressed at the specified $50 \mathrm{MPa}$ in a dedicated fixture (10-stack method).

\section{Holding Points}

Holding points have been incorporated in the organization of the cable contract to obtain a high degree of confidence in the fabrication.

- The first holding point for the strand manufacturer is the billet approval issued when the measurements performed on billet samples at the company and at CERN demonstrate that the billet is in conformity to the strand TS.

- The second holding point concerns the presentation of the cabling run and the approval of the cable maps. CERN checks that all the strands used for cabling come from previously approved billets. It is also at this moment that the duration of the final cable HT is communicated to the supplier. A coating thickness slightly different than the specification value, can namely lead to a non standard HT.

- During the cabling run representative cable samples have to be cut off and sent to CERN. CERN will measure the
TABLE II

CONTRACTS

\begin{tabular}{lllll}
\hline Company & Country & Cable 01 & Cable 02 & Cable 03 \\
\hline Alstom & France & 5 octants & 3 octants & 3 octants \\
Europa Metalli & Italy & - & 2 octants & 2 octants \\
Furakawa & Japan & - & 1 octant & 1 octant \\
IGC & USA & - & 1 octant & 1 octant \\
Outokumpu & Finland & - & 1 octant & 1 octant \\
Vacuumschmelze & Germany & 3 octants & - & - \\
\hline
\end{tabular}

1 octant cable $01=616$ unit lengths of $460 \mathrm{~m}$

1 octant cable $02=616$ unit lengths of $750 \mathrm{~m}$

1 octant cable $03=108$ unit lengths of $660 \mathrm{~m}$

cable critical current, the edge conditions, and all the other cable characteristics necessary to check its conformity. Upon positive results and after receiving the complete and correct data and the certificate of conformity CERN issues the approval for shipment.

- Upon the cable reception at CERN, a dimensional control of the entire cable and the final measurement of $R c$ are performed. The certificates and the data are checked and the provisional acceptance is given if all conforms to the cable TS.

\section{CERN MEASUREMENT EQUIPMENT}

A specific measurement laboratory has been set-up at CERN to perform the huge number of measurements. Incoming samples are labeled, cut and then dispatched to the following measurement stations (in parentheses are indicated the capacity of the test station given as the number of strand/cable samples that can be measured weekly).

Measurements at Room Temperature:

- 1 installation for $\mathrm{Cu} / \mathrm{SC}$ measurements (300 s/week),

- equipment to measure the strand bending, the filament twist pitch, the strand spring back and the strand diameter (300 s/week),

- 2 installations to measure the $\mathrm{SnAg}$ coating thickness (300 s/week) via the coulometric method,

- 2 installations to measure the $\mathrm{SnAg}$ coating thickness (70 s/week) via the Atomic Absorption methodology (AAS),

- Equipment to measure the contraction of the cable during coil curing (5 ULs/week),

- 3 lines for the dimensional measurements of the cable partially equipped with an optical inspection system to check for cold-welds and strand cross-overs (30 ULs/week),

- Equipment to control the cable edges (45 ULs/week),

- Equipment to perform the cable sharp bend test (45 ULs/week),

- Equipment to measure the cable mid-thickness on a stack of 10 cable pieces (30 ULs/week).

Measurements at 1.9/4.2 K:

- 1 test station to measure the strand magnetization at $4.2 \mathrm{~K}$ and $1.9 \mathrm{~K}$ (35 s/week) [7],

- 1 test station to measure the strand RRR at $4.2 \mathrm{~K}$ (230 $\mathrm{s} /$ week),

- 1 test station to measure $R c$ at $4.2 \mathrm{~K}$ (16 s/week), 
TABLE III

Main StRAND CRITICAL CURRENTS AT $1.9 \mathrm{~K}$

\begin{tabular}{lllllll}
\hline Supplier & $\mathrm{I}_{C, \text { aver }}$ & $\sigma$ & $\left(\mathrm{I}_{\mathrm{C}, \max }-\mathrm{I}_{\mathrm{C}, \min }\right) / \mathrm{I}_{\mathrm{C}, \text { aver }}$ & $\mathrm{CV}$ & $\mathrm{Jc}_{\mathrm{c}, \mathbf{a v g}}$ & $\sigma$ \\
& {$[\mathrm{A}]$} & {$[\mathrm{A}]$} & {$[\%]$} & {$[\%]$} & {$[\mathrm{A} / \mathrm{mm} 2]$} & {$[\mathrm{A} / \mathrm{mm} 2]$}
\end{tabular}

\begin{tabular}{lcrrrrr}
\multicolumn{2}{l}{ Cable 01 @ 10 T } & & & & & \\
B & 566 & 14.9 & 18.3 & 2.6 & 1695 & 43 \\
E & 572 & 11.6 & 10.7 & 2.0 & 1699 & 31 \\
Cable 02 @ 9 T & & & & & \\
B & 423 & 9.3 & 12.6 & 2.2 & 2347 & 42 \\
C & 419 & 9.3 & 12.3 & 2.2 & 2301 & 42 \\
G & 430 & 8.6 & 11.5 & 2.0 & 2372 & 33 \\
K & 411 & 5.8 & 7.1 & 1.4 & 2257 & 28 \\
\hline
\end{tabular}

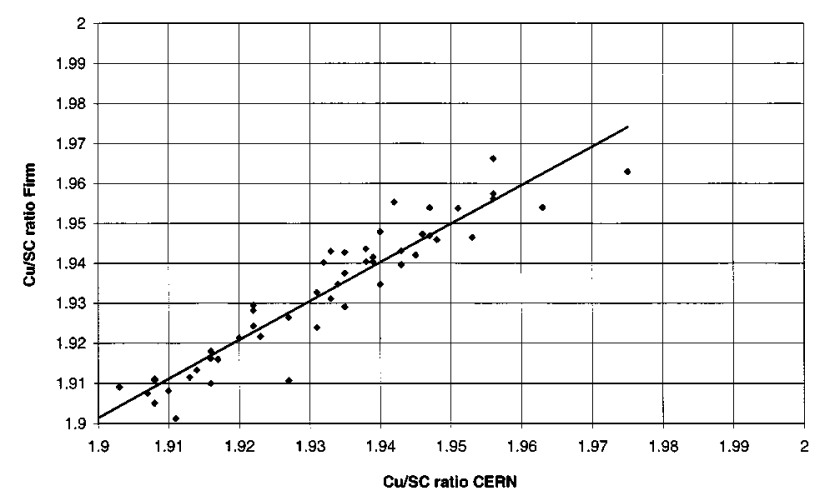

Fig. 2. Correlation between the $\mathrm{Cu} / \mathrm{SC}$ ratio measurement between a company and CERN.

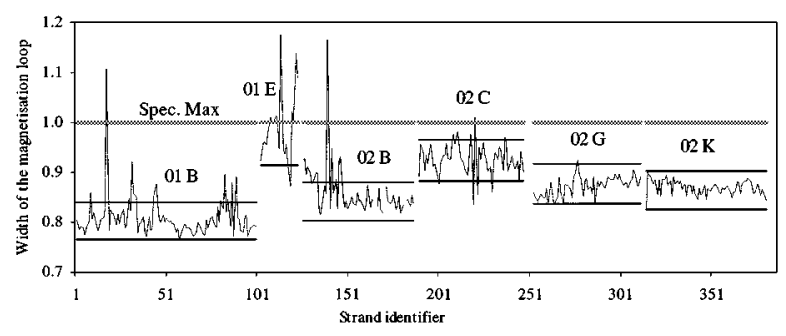

Fig. 3. Measured values of the width of the magnetization loop at $1.9 \mathrm{~K}, 0.5$ $\mathrm{T}$, normalized on the specified value of $30 \mathrm{mT}$ for strand 01 and $23 \mathrm{mT}$ for strand 02 . The results are plotted in chronological order for each company. The indicated control limits are at $\pm 4.5 \%$ of the center line.

- 4 test stations to measure the strand critical currents at 4.2 $\mathrm{K}$ and $1.9 \mathrm{~K}$ (sub-cooled) and at fields between 5 and 11 $\mathrm{T}$ (180 s/week) [8],

- 1 test station to measure the cable critical currents at 4.2 $\mathrm{K}$ and $1.9 \mathrm{~K}$ (sub-cooled) and at fields between 6 and 10.3 T, uniform over $1 \mathrm{~m}$ (4 s/week) [9], [10].

A large zone is installed for the reception and storage of cables for up to 400 magnets. Additionally, a large number of cable critical current measurements (up to $16 \mathrm{~s} /$ week) is performed at BNL as part of the U.S. contribution to the LHC.

\section{RESULTS}

Some measured results of the most important characteristics of the specifications, such as $I_{C}, \mathrm{Cu} / \mathrm{SC}$ ratio, Magnetization, cable dimensions, cable $I_{C}$ are presented in the next sections.

\section{A. Strand Critical Current at $1.9 \mathrm{~K}$}

Table III shows the results of the strand critical current measurements performed at CERN at $1.9 \mathrm{~K}$. All the critical currents measured on the strands are above the minimum specified limit. For all the companies the Process Capability Ratio Cpk [11] is above 1.35 , indicating that the limits in the process are well above the lower specification limit.

The overall Coefficient of Variation (CV) for each supplier is defined as the standard deviation divided by the average value of the sample set produced up to now. A small CV indicates a small variability in all the processes that influence the critical current. It is expected that the variation in the strand $I_{C}$ will decrease further, but unfortunately this criterion of $\pm 4 \%$ around the average is not yet fulfilled for all companies. It is interesting to mention that the field shift at the same current between $4.2 \mathrm{~K}$ and $1.9 \mathrm{~K}$ varies from $2.9 \mathrm{~T}$ to $3.05 \mathrm{~T}$ depending on the supplier.

\section{B. Copper to Superconductor $(\mathrm{Cu} / \mathrm{SC})$ Ratio}

The $\mathrm{Cu} / \mathrm{SC}$ ratio is measured by the chemical etching method for the absolute value measurement. The control of the homogeneity of the $\mathrm{Cu} / \mathrm{SC}$ ratio all over the length of the billet is performed by an on-line electrical method at the companies premsies.

Fig. 2 shows a typical correlation between the measured $\mathrm{Cu} / \mathrm{SC}$ ratio at CERN and in a company, both obtained by chemical etching. The values do not differ by more than 0.01 when the test procedures are fully respected. In specific cross-checks, the difference is lower than 0.005 .

\section{Magnetization}

Fig. 3 shows the measured values of the width of the magnetization loop at $1.9 \mathrm{~K}, 0.5 \mathrm{~T}$, normalized on the specified value of $30 \mathrm{mT}$ for strand 01 and $23 \mathrm{mT}$ for strand 02 .

The figure shows that the values are slightly below the specification limit except for a few billets which have shown extremely high values and have been rejected. It has been demonstrated that the origin of these high values is mainly related to an exceptional large deformation of the filaments, and not to an increase in $J_{C}$ at low field.

Fig. 4(a)-(d) show these deformed filaments and the related value of the magnetization. The deformation of the filaments has its origin during extrusion and can occur in single stack [Fig. 4(a)-(c)] as well as in double stack assembly [Fig. 4(d)].

All the strand manufacturers have taken action to provide better follow-up at the billet assembly and at the extrusion (temperature, time, speed, and pressure) to avoid the rejection of billets for magnetization reasons.

\section{Cable Dimensions}

All the reported dimensional measurements in this section have been performed at CERN on heat treated ULs using the CMM (Cable Measurement Machine), in combination with the absolute value obtained from the 10 -stack method.

Fig. 5 shows the measurement of the mid-thickness of cables 02 supplied by all the vendors, and indicates the upper and lower Specification Limits. The result yields an average of $1.480 \mathrm{~mm}$ 


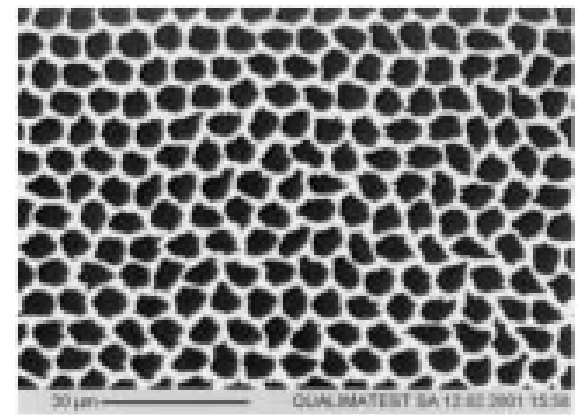

(a)

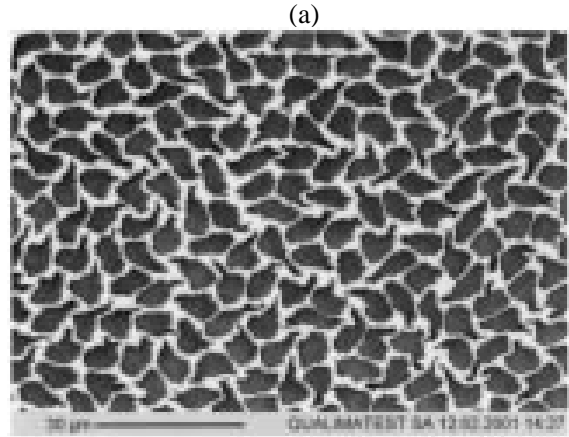

(b)

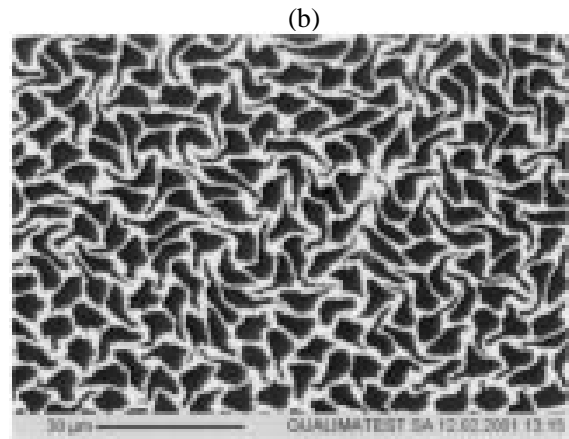

(c)

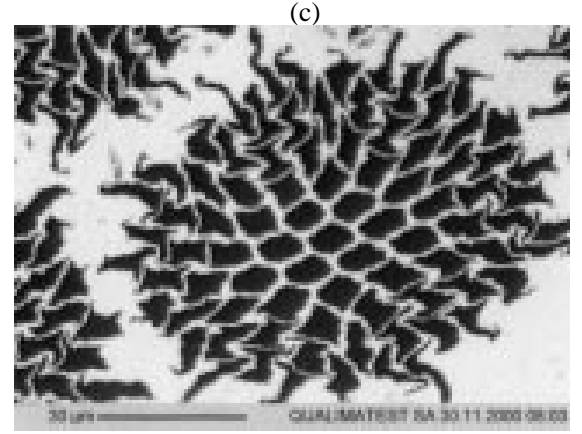

(d)

Fig. 4. Cross-section of a single stack 02 strand for (a) non deformed, (b) deformed, (c) heavily deformed filaments. Fig. 4(d) shows the cross-section of a double-stack 01 strand with heavily deformed filaments. The corresponding magnetization values are $19,22,26.8$, and $35 \mathrm{mT}$.

with a standard deviation of $2 \mu \mathrm{m}$, and is therefore in very good agreement with the specified value of $1.480 \pm 0.006 \mathrm{~mm}$.

Fig. 6 is a distribution diagram of the mid-thickness of all the cables 01 supplied to CERN. Also for cables 01 the thickness is well within the specification limits.

During the cable measurements, it has been demonstrated by an intensive program of tests that the cables keep their transverse dimensions to within $1 \mu \mathrm{m}$ even when the heat treated cable is respooled several times.

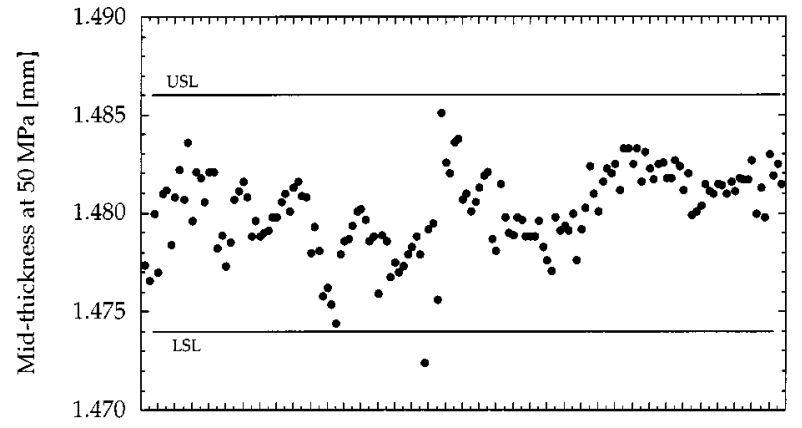

Fig. 5. Mid thickness at $50 \mathrm{MPa}$ of the cables 02 measured at CERN for all the unit lengths produced by the various companies.

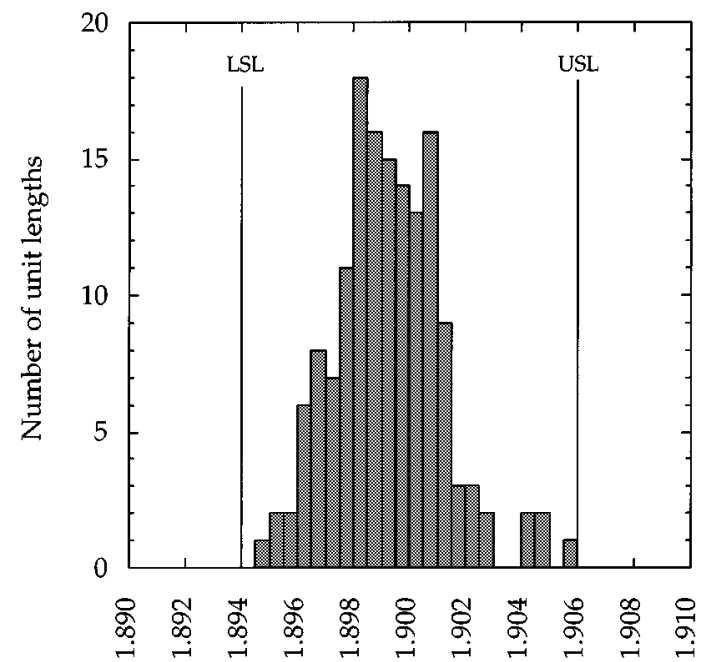

Fig. 6. Distribution of the mid thickness at $50 \mathrm{MPa}$ for all the unit lengths of cable 01 produced by the various companies (average $=1.900 \mathrm{~mm}, \sigma=0.002$ $\mathrm{mm})$.

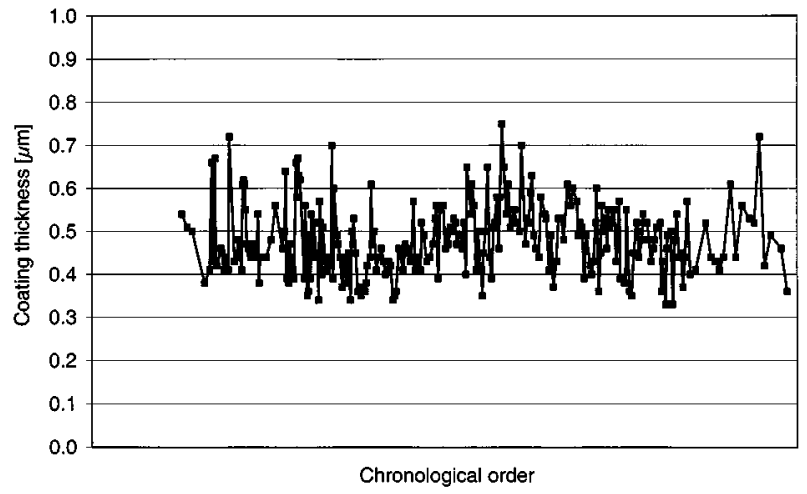

Fig. 7. Strand coating thickness for strands type 02 from one company.

The delivered cables do not present any sharp edges outside the $0.1 \mathrm{~mm}$ specified value due to a good cabling mandrel design which is well positioned in the Turk's head rollers. The typical cabling speed is $0.1 \mathrm{~m} / \mathrm{s}$.

\section{E. Cable Critical Current at $4.2 \mathrm{~K}$}

The critical current of all the measured cables (see Table IV) are above the specified values by about $10 \%$. The highest $\mathrm{CV}$ for the cable is $2 \%$ indicating that variations in the strand $I_{C}$, cable 
TABLE IV

CABle Critical CuRrents at $4.222 \mathrm{~K}$

\begin{tabular}{lllll}
\hline Supplier & $\begin{array}{l}\text { Average Ic } \\
\text { [A] }\end{array}$ & $\begin{array}{l}\sigma \\
\text { [A] }\end{array}$ & $\begin{array}{l}\text { Cv } \\
{[\%]}\end{array}$ & $\begin{array}{l}\text { Degradation } \\
{[\%]}\end{array}$ \\
Cable 01 @ 7 T & & & \\
B & 14804 & 289 & 2.0 & -2.7 \\
E & 15504 & 139 & 0.9 & -1.9 \\
Cable 02 @ 6 T & & & \\
B & 14841 & 243 & 1.6 & -2.6 \\
C & 14623 & 135 & 0.9 & -1.6 \\
G & 15298 & 159 & 1.0 & -2.0 \\
K & 14894 & 182 & 1.2 & -2.7 \\
\hline
\end{tabular}

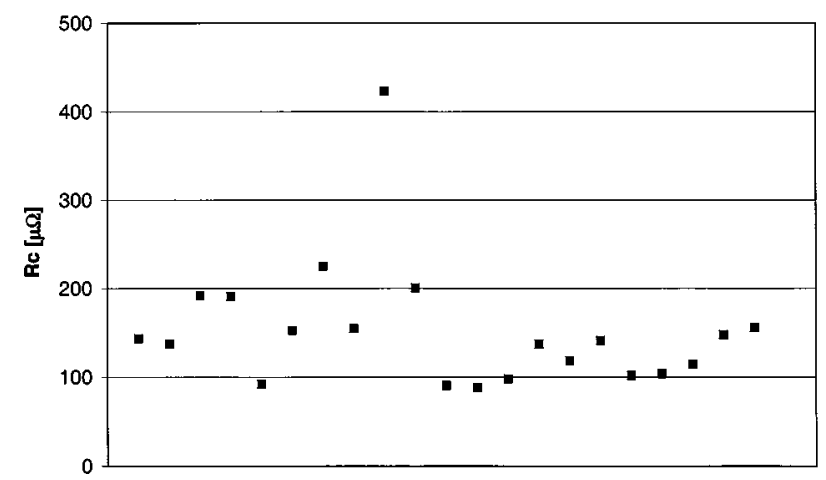

Fig. 8. $R c$ value on heat treated cables type 02 of one company.

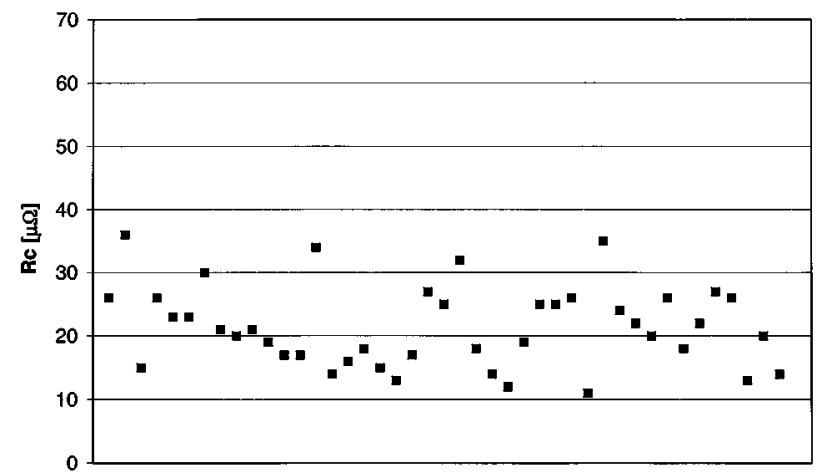

Fig. 9. $R c$ value along the length of a given UL of cable type 01 .

transposition pitch, and cabling degradation do not contribute more than $2 \%$ to the $I_{C}$ variation of the final cable.

\section{F. Cross-Contact Resistance}

Coating thickness is measured using the coulometric method both by the company and at CERN, and by the AAS method at CERN. Fig. 7 shows as an example the Atomic Absorption results on strands type 02 from one company since the start of the contract. The thickness is well controlled with a standard deviation of about $0.08 \mu \mathrm{m}$.

Fig. 8 shows the $R c$ value as measured on finished (heat treated) cables from one company. It shows that $R c$ is rather constant but still larger than the required value of $20-40 \mu \Omega$. This problem will be solved by a small increase in the coating thickness or a decrease in the heat treatment duration.

Fig. 9 shows the variation of $R c$ along the length of one UL. The uniformity is very satisfactory, and confirms the tempera-

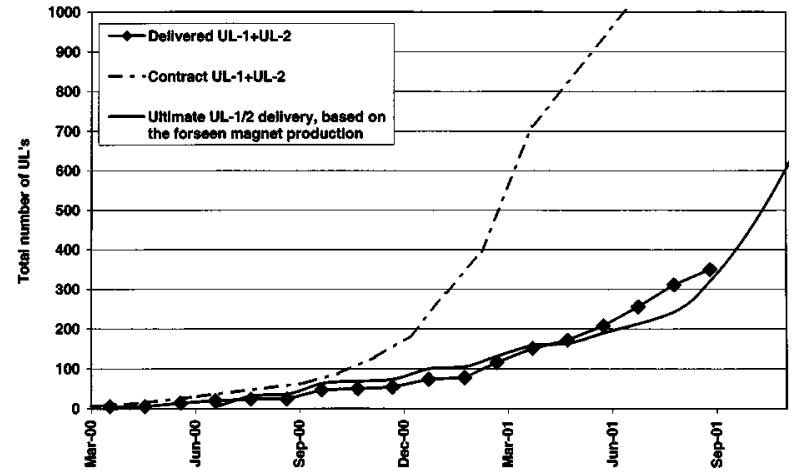

Fig. 10. Actual cable delivery as compared to the contractual delivery and the requested delivery for a foreseen magnet production rate of 5 magnets/week in April 2002 and 8 magnets/week in May 2003.

ture homogeneity inside the entire spool during the heat treatment .

\section{DELIVERY}

The delivery of the raw material follows the expected delivery. At present (Sept. 2001) 199.6 tons of NbTi and 12.2 tons of $\mathrm{Nb}$ sheets have already been delivered and accepted by the European strand manufacturers. This corresponds to about $42 \%$ of the contract. The $47 \%$ weight $\mathrm{Ti}$ is controlled within $\pm 1.0 \%$ at the center and at the periphery of the bars.

The produced cables are delivered with a delay of around one year compared with the contractual terms (see Fig. 10). The reasons of the delays are mainly the setting-up of new high production-rate lines with new machines to be commissioned and larger than expected number of wire breakages. The situation is now improving, mainly by removing in the plants the source of strand breakages (principally due to inclusions).

The production rate is expected to increase in all the companies in the period between September 2001 and March 2002 sufficiently to follow the planning. In Fig. 10 are presented the actual cable deliveries, the contractual deliveries, and the requested deliveries based on a foreseen magnet production rate of 5 magnets per week starting in April 2002 and increasing to 8 magnets per week in May 2003. For the time being, the cable production does not jeopardize the LHC project but it is vital to increase the delivery rate in the near future.

\section{CONCLUSION}

The contracts for the LHC superconducting cables, representing during 5 years more than $28 \%$ of the annual production of superconductor in cost terms, have been signed in 1998. Seven companies, in Europe, the USA and Japan, are involved in this work.

All the NbTi and Nb is supplied by Wah-Chang; it is within the specification and is being delivered in due time.

All the strand manufacturers are able to fulfill the very demanding LHC specifications. Unfortunately a larger magnetization than specified, due to a large filament deformation originating during the extrusion process, has caused the rejection of a small number of billets. Corrective action has been taken. The inter-strand contact resistance is controlled by a strict con- 
trol of the strand coating thickness associated with an adequate cable heat treatment on the spools. The obtained values are still a factor 2-3 larger than necessary for field quality reasons. The uniformity along a unit length of cable is very good.

The cable $I_{C}$ is about $10 \%$ larger than the specified value, and the cable dimensions are well within the specified limits.

Quality control is performed both at the company's premises and at CERN. The correlation between the CERN and the company's measurements is very good, allowing a precise follow-up of the production.

The delays in cable deliveries are worrying but fortunately do not cause at present any delay on the LHC project. These delays have been caused by commissioning of new equipment and wire breakages. The number of wire breakages is decreasing and it is expected that the production rate will significantly increase in the near future.

The CERN test equipment for reception and acceptance of the LHC strands and cables can face the future high peak of production rate necessary to compensate for the delays in delivery of the initial phase of the LHC cable production.

\section{ACKNOWLEDGMENT}

The authors express their gratitude to all the personnel of the companies participating in the LHC superconductor project, to the CERN management for their support and constant interest, and to the Japanese and American contributions.

They thank especially A. Ghosh for the cable measurements at BNL, R. Scanlan for its assistance in cabling, and A. Knezovic for the CERN laboratory installation. They warmly thank E. Charifoullina, N. Emelianenko, and G. Bianchi for their support in the data base implementation and graphics software; R. Monod for the cable $I_{C}$ measurements, A. Bonasia, S. Geminian, P. Jacquot, J. L. Servais, and J. Stott for the daily highly qualified technical support; and the personnel of the industrial support operating in the laboratory. The achievement of the cable reception laboratory is the result of a fruitful collaboration between the MMS-SC, IAS, and ECR groups.

\section{REFERENCES}

[1] The LHC Study Group, "The large hadron collider, conceptual design," CERN/AC/95-05, 1995.

[2] S. Le Naour, L. R. Oberli, R. Wolf, R. Puzniak, A. Szewczyk, A. Wisniewski, H. Fikis, H. M. Foitl, and H. Kirchmayr, "Magnetization measurements on LHC superconducting strands," IEEE Trans. Appl. Superconduct., pt. 2, vol. 9, no. 2, pp. 1763-1766, 1999.

[3] R. Wolf and S. Le Naour, "The expected persistent current field errors in the LHC main dipole and quadrupole," CERN, Geneva, Switzerland, LHC Project Note 230, 2000

[4] A. P. Verweij and R. Wolf, "Field errors due to interstrand coupling currents in the LHC dipole and quadrupole,", CERN Internal Note AT/MA 94-97, 1995.

[5] D. Richter, J. D. Adam,, J.-M. Depond, D. Leroy, and L. R. Oberli, "DC measurement of electrical contacts between strands in superconducting cables for the LHC main magnets," IEEE Trans. Appl. Superconduct., vol. 7, no. 2, pp. 786-792, 1997

[6] D. Richter, J. D. Adam, D. Leroy, and L. R. Oberli, "Strand coating for the superconducting cables of the LHC main magnets," IEEE Trans. Appl. Superconduct., vol. 9, no. 2, pp. 735-741, 1999.

[7] S. Le Naour, R. Wolf, J. Billan, and J. Genest, "Test station for magnetization measurements on large quantities of superconducting strands," IEEE Trans. Appl. Superconduct., pt. 3, vol. 11, no. 1, pp. 3086-3089, 2000.

[8] T. Boutboul, C.-H. Denarie, Z. Charifoulline, L. Oberli, and D. Richter, "Critical current test facilities for LHC superconducting NbTi cable strands," in EUCAS 2001, 5th European Conf. Applied Superconductivity, Copenhagen, Aug. 26-30, 2001, submitted for publication.

[9] A. P. Verweij, J. Genest, A. Knezovic, D. Leroy, J.-P. Marzolf, and L. Oberli, " $1.9 \mathrm{~K}$ test facility for the reception of the superconducting cables for the LHC," IEEE Trans. Appl. Superconduct., vol. 9, pp. $153-156,1998$

[10] A. P. Verweij and L. Buchsbaum, "Experimental results of current distribution in Rutherford-type LHC cables," Cryogenics, vol. 40, pp. 663-670, 2000

[11] D. C. Montgomery, Introduction to Statistical Quality Control, Third ed: John Wiley \& Sons, Inc., 1996. 